\title{
Gefitinib Inhibits the Growth of Toxoplasma gondii in HeLa Cells
}

\author{
Zhaoshou Yang, Hye-Jin Ahn, Ho-Woo Nam* \\ Department of Parasitology, College of Medicine, The Catholic University of Korea, Seoul 137-701, Korea
}

\begin{abstract}
Toxoplasma gondii is the causative agent of toxoplasmosis with symptoms of congenital neurological and ocular diseases and acquired lymphadenitis, retinochoroiditis, and meningoencephalitis. Small molecules which block the activity of protein kinases were tested in in vitro culture of $T$. gondii to find new therapeutic drugs of safer and more effective than the combined administration of pyrimethamine and sulfadoxine that sometimes provoke lethal Stevens-Johnson syndrome. Among them, Gefitinib and Crizotinib inhibited intracellular growth of $T$. gondii in HeLa cells by counting the number of $T$. gondii per parasitophorous vacuolar membrane whereas Sunitinib did not. Gefitinib inhibited the growth of $T$. gondii in a dose-dependent manner over $5 \mu \mathrm{M}$ up to the tolerable concentration of HeLa cells and halted the division of the parasite immediately from the time point of treatment. Gefitinib inhibition suggests that tyrosine kinases of EGFR family or other homologous kinases of the parasite itself may be the target to cause the block of $T$. gondii growth.
\end{abstract}

Key words: Toxoplasma gondii, toxoplasmosis, treatment, small molecule, Gefitinib, EGFR tyrosine kinase, rhoptry kinase

Toxoplasma gondii, an apicomplexan obligate intracellular parasite, is the causative agent of toxoplasmosis among mammals and birds, including humans of one-third worldwidely. The majority of human infection is benign, and the disease is asymptomatic [1]. In a small percentage of acquired infections, lymphadenitis may occur, if not treated, which leads to a chronic cyst formation in the central nervous system or muscle. Retinochoroiditis and meningoencephalitis occur in newly infected and reactivated cases with brain cysts [2,3].

Combined administration of pyrimethamine and sulfadoxine is the method of choice in the treatment of symptomatic toxoplasmosis in vivo [1]. Pyrimethamine inhibits specifically dihydrofolate reductase-thymidylate synthase complex of the parasite to block the synthesis of DNA, RNA, and protein, and sulfadoxine inhibits the growth of the parasite synergistically. However, relatively long-term administration for 1 month of sulfadoxine may provoke severe Stevens-Johnson syndrome in sulfa-sensitive patients who have not been aware of their susceptibility until experienced. At this point of view, it is neces-

- Received 17 March 2014, revised 14 May 2014, accepted 24 June 2014.

*Corresponding author (howoo@catholic.ac.kr)

(c) 2014, Korean Society for Parasitology and Tropical Medicine

This is an Open Access article distributed under the terms of the Creative Commons Attribution Non-Commercial License (http://creativecommons.org/licenses/by-nc/3.0) which permits unrestricted non-commercial use, distribution, and reproduction in any

medium, provided the original work is properly cited. sary to find out new drugs which are equivalent in effects but safer to cure symptomatic toxoplasmosis. Recently, many protein kinases of T. gondii have been identified and characterized to play crucial roles in the proliferation and differentiation of the parasite [4], in addition to rhoptry kinases which are secreted to the parasitophorous vacuolar membrane (PVM) to interact with host molecules for the survival and growth of intracellular parasites [5]. Regardless of uniqueness to T. gondii, these protein kinases can be inhibited by so called 'small molecules' which have been developed for chemotherapy of various types of cancer [6].

Three kinds of small molecules were tested for inhibition of intracellular growth of T. gondii (RH strain) in HeLa cells (ATCC CCL-3, Manassas, Virginia, USA) with the control of pyrimethamine. Those are Gefitinib (ZD-1839), an EGFR inhibitor; Sunitinib malate (SU11248), an inhibitor of VEGFR2 and PDGFR $\beta$; and Crizotinib (PF-2341066), a cMet and ALK inhibitor, purchased from Selleck Chemicals (Houston, Texas, USA). HeLa cells were cultured on 12-mm cover glasses in 24-well plates (Costar, New York, USA) at $0.5 \times 10^{5} \mathrm{cell} / 0.5 \mathrm{ml} /$ well. After $24 \mathrm{hr}$ of plating, fresh RH tachyzoites of T. gondii were added at $5.0 \times 10^{5} / 0.5 \mathrm{ml} /$ well for $1 \mathrm{hr}$ challenge, then not invading parasites were washed out with DPBS and refilled with fresh medium containing 10\% FBS. Drugs were added at $1 \mathrm{hr}$ of post infection in experiments. At the indicated time point of post in- 
A

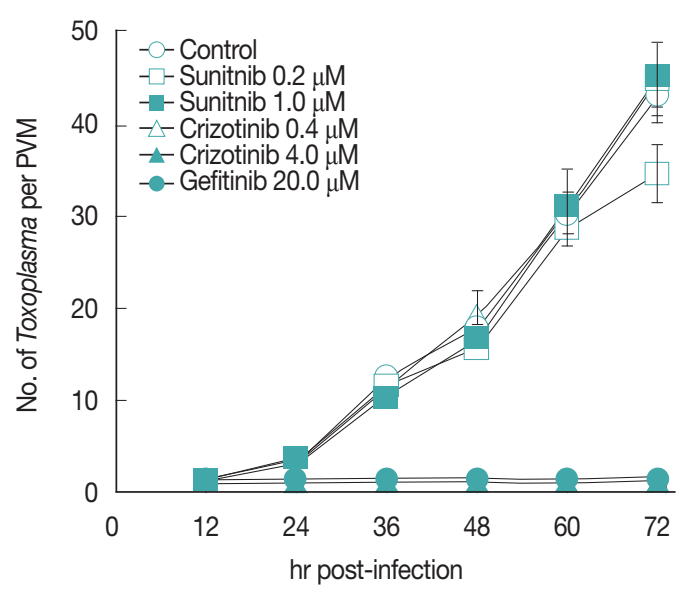

B

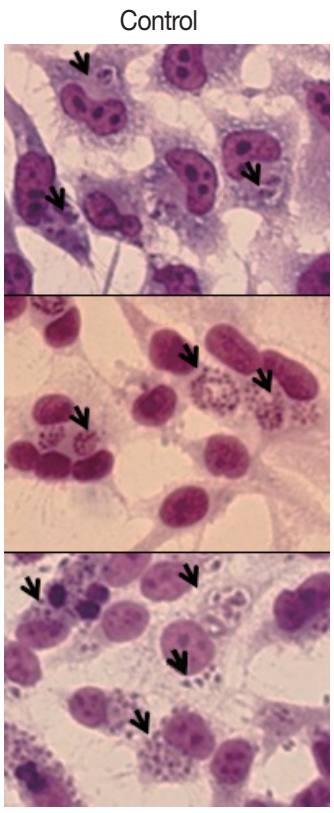

Gefitinib 20

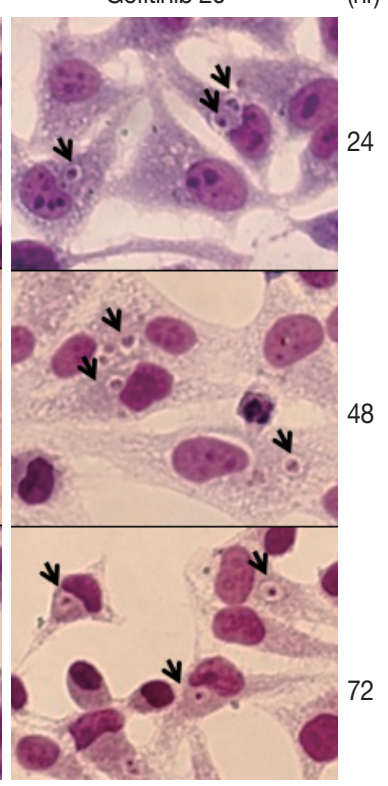

(hr)

24

8

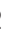

Fig. 1. Gefitinib efficiently inhibits the intracellular multiplication of T. gondii RH strain in HeLa cells. (A) Parasite counting results after treatment with small molecules. Data are means \pm SD for duplicate wells. (B) The representative result of Giemsa stain. Control; intracellular growth of T. gondii without any treatment, and Gefitinib 20; $20 \mu \mathrm{M}$ Gefitinib treated. Arrows indicate PVM.

fection, cells were fixed and stained with modified Giemsa stain solution (Sigma Aldrich, St. Louis, Missouri, USA). Tachyzoites within PVM were counted at 20 sites and presented as the mean number of tachyzoites per PVM with SD.

All 3 small molecules did not influence the invading activity of $T$. gondii to the host cells, but were treated after $1 \mathrm{hr}$ challenge of $T$. gondii to exclude the effect on the penetration. As shown in Fig. 1, Gefitinib of $20 \mu \mathrm{M}$ inhibited the growth of $T$. gondii completely as one organism per PVM until $72 \mathrm{hr}$ just as the initiating challenge without detachment of host HeLa cells, which showed the equivalent inhibitory effect of pyrimethamine of $5.0 \mu \mathrm{M}$ (data not shown). Crizotinib of $4.0 \mu \mathrm{M}$ also inhibited the growth of the parasite, but the majority of host HeLa cells were affected to be detached from the culture plate. Crizotinib of $0.4 \mu \mathrm{M}$ did not show the effect on the growth of T. gondii. In the meantime, Sunitinib over $1.0 \mu \mathrm{M}$ affected severely to detach the host HeLa cells; therefore, observing or counting the intracellular parasite was not available. Sunitinib of $1.0 \mu \mathrm{M}$ or less did not affect the growth of intracellular $T$. gondii. Gefitinib inhibited the growth of T. gondii in a dose-dependent manner over $5 \mu \mathrm{M}$ to tolerable concentration of host HeLa cells (Fig. 2A), of which the concentration of less than 5 $\mu \mathrm{M}$ showed a little effect, while over $10 \mu \mathrm{M}$ clearly inhibited the growth. When treated at $24 \mathrm{hr}$ or $48 \mathrm{hr}$, Gefitinib halted the growth of T. gondii from the time of treatment (Fig. 2B).
Gefitinib targets tyrosine kinase of EGFR [7] and Crizotinib targets tyrosine kinases of cMet and ALK as a substitute against Gefitinib resistance caused by the mutations in EGFR [8] of cancer cells. Growth inhibition of the intracellular T. gondii by Gefitinib and also by Crizotinib suggests the crucial role of the tyrosine kinases of EGFR family [6] for survival and growth of the parasite within host cells. Under the environment of intracellular parasite-host cells and further in case of T. gondii where the intracellular parasites are partitioned separately from the host cytoplasm with PVM, it may be more complex to identify and characterize the target for Gefitinib than in relatively simple cancer cells. As depicted in cancer cells, Gefitinib blocks downstream of EGFR activation of signaling molecules such as AKT, ERK, JNK, and MAPK p38, which modifies intracellular niche to inhibit the growth of T. gondii in indirect manner just like the restriction of the growing Mycobacterium tuberculosis within macrophages by Gefitinib [9]. In addition to this, we propose possible candidate targets for Gefitinib more directly to the PVM and the parasite itself. Among the rhoptry kinases secreted to the PVM, a certain kinase that participate in the host-parasite relationship with structurally and functionally homologous to the tyrosine kinase of EGFR can be a target as well as EGFR-like molecules or tyrosine kinase-like molecules in T. gondii.

For the treatment of toxoplasmosis, small molecules also 
A

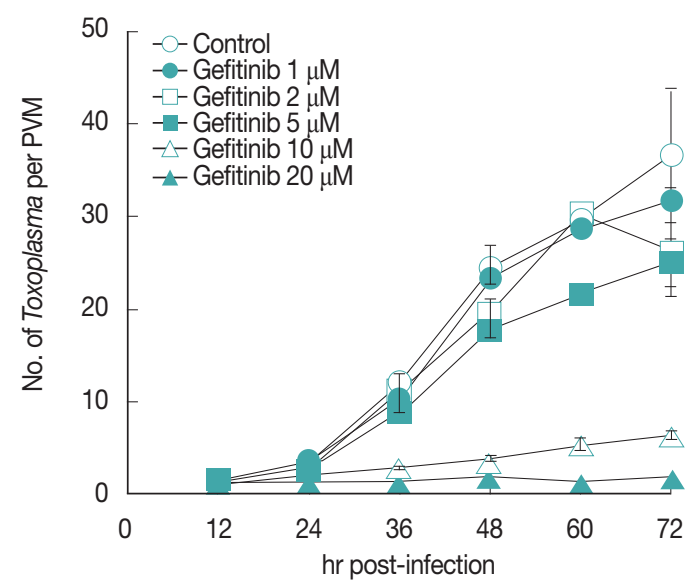

B

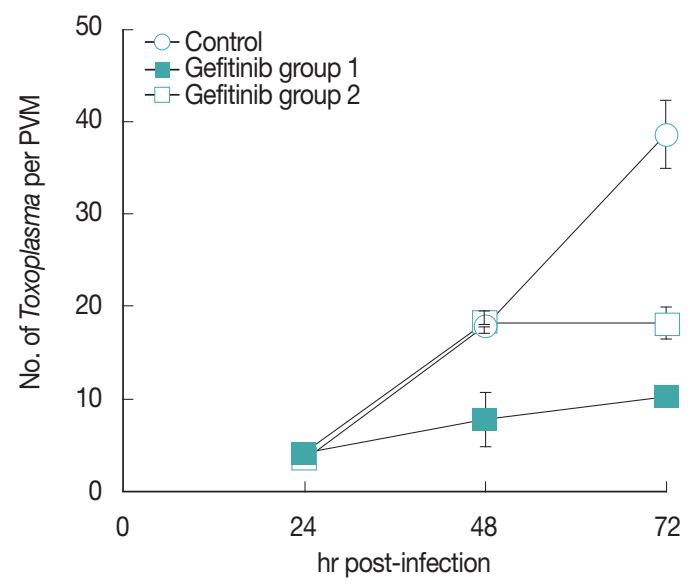

Fig. 2. Effects of Gefitinib on the growth of T. gondii. (A) Dose-dependence of Gefitinib. (B) Effect of Gefitinib during the culture of T. gondii in HeLa cells treated at $24 \mathrm{hr}$ after infection (group 1) and at $48 \mathrm{hr}$ (group 2).

have side effects of cytotoxicity to the host cells with different tolerable concentrations regardless of being infected or not. It is necessary to characterize the target tyrosine kinase of EGFR family first and to screen the small molecules or develop derivatives which follow the strategy of parasite specificity and host safety.

\section{ACKNOWLEDGMENT}

This research was partially supported by the Basic Science Research Program through the National Research Foundation of Korea (NRF) funded by the Ministry of Education, Science and Technology, Korea (NRF-2012R1A1A 2002612).

\section{CONFLICT OF INTEREST}

We have no conflict of interest related to this study.

\section{REFERENCES}

1. John DT, Petri WA (eds). The tissue coccidia: Toxoplasma gondii. Markell and Voge's Medical Parasitology (9th ed.). Elsevier Inc., USA. 2006, p 139-149.

2. Choi WY, Nam HW, Kwak NH, Huh W, Kim YR, Kang MW, Cho SY. Foodborne outbreaks of human toxoplasmosis. J Infect Dis 1997; 175: 1280-1282.
3. Park YH, Han JH, Nam HW. Clinical features of ocular toxoplasmosis in Korean patients. Korean J Parasitol 2011; 49: 157-171.

4. Wei F, Wang W, Liu Q. Protein kinases of Toxoplasma gondii: functions and drug targets. Parasitol Res 2013; 112: 2121-2129.

5. Qui W, Wernimont A, Tang K, Taylor S, Lunin V, Schapira M, Fentress S, Hui R, Sibley LD. Novel structural and regulatory features of rhoptry secretory kinases in Toxoplasma gondii. EMBO J 2009; 28: 969-979.

6. Zhang J, Yang PL, Gray NS. Targeting cancer with small molecule kinase inhibitors. Nature Rev (Cancer) 2009; 9: 28-39.

7. Garofalo M, Romano G, Di Leva G, Nuovo G, Jeon YJ, Ngankeu A, Sun J, Lovat F, Alder H, Condorelli G, Engelman JA, Ono M, Rho JK, Cascione L, Volinia S, Nephew KP, Croce CM. EGFR ad MET receptor tyrosine kinase-altered microRNA expression induces tumorigenesis and Gefitinib resistance in lung cancers. Nature Med 2012; 18: 74-82.

8. Cui JJ, Tran-Dubé M, Shen H, Nambu M, Kung PP, Pairish M, Jia L, Meng J, Funk L, Botrous I, McTigue M, Grodsky N, Ryan K, Padrique E, Alton G, Timofeevski S, Yamazaki S, Li Q, Zou H, Christensen J, Mroczkowski B, Bender S, Kania RS, Edwards MP. Structure based drug design of Crizotinib (PF-02341066), a potent and selective dual inhibitor of mesenchymal-epithelial transition factor (c-MET) kinase and anaplastic lymphoma kinase (ALK). J Med Chem 2011; 54: 6342-6363.

9. Stanley SA, Barczak AK, Silvis MR, Luo SS, Sogi K, Vokes M, Bray MA, Carpenter AE, Moore CB, Siddiqi N, Rubin EJ, Hung DT. Identification of host-targeted small molecules that restrict intracellular Mycobacterium tuberculosis growth. PLoS Pathog 2014; 10: 1-16. 
